\title{
Monitoramento da qualidade físico-química da água do rio Bacacheri, Curitiba - Paraná
}

- Brasil

Vera Lucia Pereira dos Santos*, Rodrigo Santiago Godefroid ${ }^{\star \star}$, Rodrigo de Cássio da Silva ${ }^{\star \star \star}$, Fábio Branco Godinho de Castro ${ }^{\star \star \star \star}$, Rodrigo Bertée

\section{Resumo}

O crescimento desordenado da cidade de Curitiba, capital do Estado do Paraná (Brasil), fez com que ocorresse um aumento das ações antropogênicas sobre a maioria dos seus rios urbanos como, por exemplo, o lançamento de esgoto in natura, o despejo de lixo doméstico e industrial, a alteração do seu leito e o desmatamento da mata ciliar, que acabaram determinando a degradação desses corpos d'água. O rio Bacacheri, um dos rios mais impactados da área urbana de Curitiba, tem sua nascente no bairro Cachoeira, situado na região norte da cidade, atravessando 16 bairros ao longo dos seus $12 \mathrm{~km}$ de extensão. Nesse contexto, o objetivo do presente trabaIho foi investigar a qualidade da água do rio Bacacheri através de parâmetros físico-químicos em quatro (04) diferentes pontos de coleta entre os meses de junho a novembro (exceto agosto) do ano de 2016. Os resultados obtidos apontam que nas áreas mais próximas a sua nascente e sua foz, o rio Bacacheri é facilmente biodegradável e nas suas áreas intermediárias ele é passível de degradação em maior grau comparado aos outros pontos de coleta. Embora a sua turbidez esteja abaixo do limite estabelecido pela portaria que dispõe sobre os procedimentos de controle e de vigilância da qualidade da água para consumo humano e seu padrão de potabi-

* Doutoranda em Medicina Interna na Universidade Federal do Paraná (UFPR). Coordenadora do Curso Superior de Tecnologia em Estética e Cosmética do Centro Universitário Internacional Uninter. e-mail: vera.s@uninter.com

* Doutor em Ciências Biológicas com ênfase em Zoologia pela Universidade Federal do Paraná (UFPR). Coordenador de cursos de Especialização na modalidade EAD do Centro Universitário Internacional Uninter. e-mail: rodrigo.g@uninter.com

*** Doutor em Biofísica pela Universidade Federal do Rio de Janeiro (UFRJ). Professor adjunto do Departamento de Biologia Estrutural, Molecular e Genética (DEBIOGEM) da Universidade Estadual de Ponta Grossa (UEPG - PR). e-mail: rodrigosilva2005@yahoo.com.br

**** Mestre em Química pela Universidade Federal de São Carlos (UFSCAr). Professor pelo Centro Universitário Autônomo do Brasil e diretor geral do LATAM Laboratório de Análises Toxicológicas e Ambientais Ltda. e-mail: fabiobgcastro@hotmail.com

*.*** Doutor em Meio Ambiente e Desenvolvimento pela Universidade Federal do Paraná (UFPR). Diretor da Escola Superior de Saúde, Biociência, Meio Ambiente e Humanidades do Centro Universitário Internacional Uninter. e-mail: rodrigo.b@uninterr.com 
lidade (Portaria 2.914/2011 do Ministério da Saúde), os demais resultados indicam que se trata de um rio poluído, sendo necessário a intervenção de órgãos governamentais competentes para possibilitar a despoluição desse rio.

Palavras-chave: Qualidade da água. Rio Bacacheri. Parâmetros físico-químicos.

\section{Introdução}

O recurso hídrico tem se tornado cada vez mais escasso não porque o seu volume está diminuindo, mas essa escassez é devida ao desperdício e a poluição resultantes, principalmente, das atividades humanas e do uso múltiplo das bacias hidrográficas (TUNDISI; TUNDISI, 2008). Essa situação vem preocupando o mundo inteiro e, para Carvalho (2007), a preocupação com a água deveria ser foco da atenção da sociedade e de cada cidadão brasileiro.

Muitas fontes de água e bacias hidrográficas já são de baixa qualidade e necessitam de remediação e tratamento. De acordo com a Agência Nacional de Águas (ANA):

A qualidade dos recursos hídricos mundiais está sob ameaça crescente à medida que aumentam as populações humanas e se expandem as atividades industriais e agrícolas, em um cenário em que as mudanças climáticas poderão provocar grandes alterações no ciclo hidrológico. Água de baixa qualidade põe em risco a saúde humana e dos ecossistemas, reduz a disponibilidade de água potável e de recursos hídricos próprios para outras finalidades, limita a produtividade econômica e diminui as oportunidades de desenvolvimento (BRASIL, 2013).

A maior disponibilidade hídrica mundial está no Brasil que, possui $28 \%$ do recurso hídrico disponível na América do Sul e concentra $12 \%$ da água doce do planeta. As bacias hidrográficas do Amazonas, São Francisco e Paraná concentram aproximadamente $80 \%$ da produção hídrica do país e cobrem cerca de $72 \%$ do território brasileiro (VICTORINO, 2007; BRASIL, 2013).

A cidade de Curitiba - capital do Estado do Paraná - tem a sua rede hidrográfica composta por seis bacias hidrográficas (IPPUC, 2010). Na bacia do rio Atuba, situa-se o rio Bacacheri, objeto deste estudo. Este corpo hídrico é predominantemente urbano e tem sua nascente no bairro Cachoeira, localizado na região norte da cidade. Ao longo dos seus $12 \mathrm{~km}$ de extensão, esse rio atravessa 16 bairros (NEVES et al., 2015), e vale ressaltar que o crescimento desordenado dessa cidade acarretou no lançamento de grandes quantidades de esgoto in natura nesse corpo hídrico provocando sérios problemas de impacto ambiental já verificado em outros estudos (GODEFROID; FONSECA; SILVA, 2014). 
Embora seja nítida a degradação ambiental do rio Bacacheri, o plano de despoluição hídrica desenvolvido pela SUDERHSA(Superintendência de Desenvolvimento de Recursos Hídricos e Saneamento Ambiental), constituiu o diagnóstico de qualidade de Água do Alto Iguaçu e o classificou como pertencente à classe 2 (SUREHMA, 1992). De acordo com a resolução do Conselho Nacional do Meio Ambiente (CONAMA) nº 357 de 18/03/2005, rios de classe 2 são aqueles cujas as águas são destinadas:

a) ao abastecimento para consumo humano, após tratamento convencional;

b) à proteção das comunidades aquáticas;

c) à recreação de contato primário, tais como natação, esqui aquático e mergulho, conforme Resolução CONAMA no 274, de 2000;

d) à irrigação de hortaliças, plantas frutíferas e de parques, jardins, campos de esporte e lazer, com os quais o público possa vir a ter contato direto; $\mathrm{e}$

e) à aquicultura e à atividade de pesca (BRASIL, 2005).

Apesar desta classificação, são notórias as alterações das qualidades cênicas do rio Bacacheri em toda a sua extensão urbana conforme já mencionado, o que permite inferir que os parâmetros físico-químicos deste corpo hídrico também estarão em não-conformidade com a legislação vigente de classificação dos corpos d'água e diretrizes ambientais para o seu enquadramento como sendo de classe 2.

A existência de certas substâncias químicas lançadas a partir de efluentes domésticos e industriais torna difícil a recuperação dos rios urbanos devido a drástica alteração que ocorre nestes ambientes (NEVES et al., 2015). Segundo os dados do Fundo Estadual de Saneamento Básico/Companhia Ambiental do Estado de São Paulo - FESB/CETESB (1969), a poluição nos corpos de água pode ser percebida principalmente através de mudanças na sua cor, temperatura, viscosidade, tensão superficial, DQO, DBO, pH, OD e nutrientes entre outros parâmetros. Assim, os parâmetros físico-químicos são necessários para a verificação da quantidade e tipo de poluente que chega até os corpos de água urbanos (NOZAKI et al., 2014).

A análise da temperatura é crucial pois esta é um fator limitante para a vida aquática, já que, além de influenciar diretamente a quantidade de oxigênio dissolvido e a estratificação térmica da coluna d'água, afeta as atividades metabólicas do indivíduo, sua reprodução, crescimento, alimentação, distribuição espacial, hábitos migratórios, entre outros (CRILLET; QUANTIN, 2006).

Adicionalmente, a concentração de íons hidrogênio dissolvidos, ou $\mathrm{pH}$, também é um parâmetro vital para a sobrevivência de espécies aquáticas, visto que afeta diretamente o metabolismo animal, além de estar relacionado com a biodisponibi- 
lidade de metais pesados na água. De acordo com Abowei (2010), os altos valores de $\mathrm{pH}$ podem ser resultado de uma alta taxa fotossintética causada pela presença de grandes florações de algas, ainda, para o mesmo autor, a faixa de $\mathrm{pH}$ entre 7 e 8,5 se torna ideal, por outro lado, pH abaixo de 4,0 é extremamente prejudicial.

Ademais, entre os principais indicadores de poluição por matéria orgânica estão o oxigênio dissolvido (OD), a demanda bioquímica de oxigênio (DBO) e a demanda química de oxigênio (DQO). A variação do oxigênio dissolvido (OD) tem influência na disponibilidade de nutrientes pois está relacionado com os processos de oxirredução desses elementos. Vale destacar que a quantidade de dióxido de carbono $\left(\mathrm{CO}_{2}\right)$ dissolvido é inversamente proporcional a quantidade de oxigênio dissolvido o que afeta diretamente a produção primária fitoplanctônica. Assim, quanto menor a quantidade de OD, maior é a acidez do corpo hídrico avaliado (LAWSON, 2011).

A análise da DBO fornece uma indicação indireta, ou estimada, da quantidade de matéria orgânica biodegradável por microrganismos após 5 dias de incubação. Já a análise DQO, é "um indicador de matéria orgânica baseado na concentração de oxigênio consumido para oxidar a matéria orgânica, biodegradável ou não, em meio ácido e condições energéticas por ação de um agente químico oxidante forte" (VALENTE, PADILHA; SILVA, 1997).

Os sólidos dissolvidos fornecem a informação de quanta matéria sólida está sendo carreada para o fluxo daquele corpo hídrico, e podem influenciar diretamente os parâmetros de condutividade da água. EM geral, quanto maior a concentração de sólidos em suspensão, maior é a condutividade (LAWSON, 2011).

Os óleos e graxas quando encontrados em corpos hídricos caracterizam o despejo de efluentes industriais e/ou domésticos, postos de gasolina, oficinas mecânicas, entre outros. Ainda, em função da sua baixa solubilidade e lenta degradação, torna-se um grave problema sobretudo quando estão em água de abastecimento público devido à dificuldade de tratamento e remoção dessas substâncias (PEREIRA, 2004).

Vale ressaltar que as avaliações de parâmetros físico-químicos e biológico dos recursos hídricos são parâmetros fundamentais para determinar esse grau de qualidade mencionado, sobretudo por serem fatores limitantes para a sobrevivência da fauna e flora aquática local e que, portanto, quando tais valores se apresentam diferentes do limite permitido pela legislação local vigente (acima ou abaixo) este recurso se torna prejudicial à saúde humana e ecossistêmica de uma maneira geral (TYAGI, SHARMA, BHAVTOSH, 2013). Ainda, de acordo com Resolução do Conselho 
Nacional do Meio Ambiente (Conama) 357/2005 (BRASIL, 2005) a análise desses parâmetros de qualidade da água deve auxiliar na modificação das políticas públicas para proteção desses ecossistemas, as quais são formuladas por várias agências de monitoramento ambiental.

Assim, a partir deste contexto, o presente artigo tem como objetivo monitorar, por meio de análises físicas e químicas, a qualidade da água do rio Bacacheri, ademais, com estes resultados pretende-se auxiliar os órgãos ambientais competentes para sua reclassificação e nas políticas públicas de despoluição deste corpo hídrico.

\section{Metodologia da Pesquisa}

\section{Caracterização da área de estudo}

A cidade de Curitiba está localizada no primeiro Planalto Paranaense, em média, à 943 metros de altitude acima do nível do mar, na região Sul do Brasil. Sendo considerada a sexta unidade federativa mais populosa do Brasil, com aproximadamente 2 milhões de habitantes (IBGE, 2012).

$\mathrm{O}$ rio Bacacheri está localizado na região nordeste da cidade e, de acordo com Ribeiro (2007) é "um afluente do rio Atuba, que por sua vez, é um dos tributários da margem direita da bacia do alto Iguaçu" (figura 1).

Geologicamente, a bacia hidrográfica do rio Bacacheri é formada por sedimentos recentes (do período Holoceno), sedimentos da formação Guabirotuba (período Terciário - Mioceno e Plioceno) e Complexo Gnáissico-Migmatítico, predominante nas áreas de nascentes do rio, além de seu um rio com declividade baixa na maior parte da sua extensão (RIBEIRO, 2007). As principais características geográficas deste rio estão resumidas na tabela 1.

Tabela 1: Características geográficas do rio Bacacheri. Fonte: Ribeiro (2007).

\begin{tabular}{l|l}
\hline \multicolumn{1}{c|}{ Área de drenagem } & \multicolumn{1}{c}{$38,81 \mathrm{~km}^{2}$} \\
\hline Coordenadas geográficas & Latitude: $25^{\circ} 21^{\prime} 04^{\prime \prime} \mathrm{S}$ à $25^{\circ} 26^{\prime} 58^{\prime \prime} \mathrm{S}$ \\
& Longitude: $49^{\circ} 16^{\prime} 15^{\prime \prime} \mathrm{W}$ à $49^{\circ} 11^{\prime} 59^{\prime \prime} \mathrm{W}$ \\
Canal principal (extensão) & $12,5 \mathrm{~km}$ \\
Canal secundário (extensão) & Rio Bacacheri-mirim $-4,5 \mathrm{~km}$ \\
\hline
\end{tabular}




\section{Amostragens}

Foram utilizados 4 pontos de coleta na extensão urbana do Rio Bacacheri para o monitoramento da qualidade da água. Adicionalmente, em cada ponto, foram realizadas 6 coletas entre os meses de maio a novembro de 2016, com exceção do mês de agosto, devido ao intenso período de chuvas no período de coleta.

Os pontos foram denominados de 01, 02, 03 e 04, tendo suas coordenadas geográficas determinadas com GPS.

O ponto 01 está localizado nas coordenadas Latitude 252ㅜ $02.08^{\circ}$ 'S e Longitude $49^{\circ} 15^{\prime} 09.72$ ”W, e está próximo a nascente do rio. Como características visuais, possui largura (entre as margens) de $1 \mathrm{~m}$ e profundidade de $50 \mathrm{~cm}$ com fundo arenoso, não apresenta assoreamento ou erosão, o fluxo de água é igual em toda a sua largura, e uma de suas margens possuem uma pequena faixa de mata ciliar e a margem oposta apresenta gramíneas.

O ponto 02 está localizado nas coordenadas Latitude $25^{\circ} 23^{\prime} 43.37$ 'S e Longitude 49¹3'15.00"O. Nesse local o rio não possui mata ciliar e, assim como o fundo, suas margens são concretadas. A largura (entre as margens) neste local é de $3 \mathrm{~m}$ e a profundidade é de $90 \mathrm{~cm}$. Seu fluxo é rápido com uma área de remanso e não foi constatado depósito de poluentes.

O ponto 03 localiza-se nas coordenadas $25^{\circ} 24^{\prime} 31.07^{\prime \prime} \mathrm{S}-4^{\circ} 13^{\prime} 09.48^{\prime}$ W. Visualmente, embora exista mata ciliar, em ambas as margens, como as amostragens ocorreram sob uma ponte, no local exato da amostragem não existe mata ciliar, a largura do rio é de $3 \mathrm{~m}$, sua profundidade é de $40 \mathrm{~cm}$, o fundo possui lodo e cascalho, o fluxo da água é relativamente rápido e pode ser observado o depósito de latas, papelão, vidros e plásticos nas margens e interior do rio.

O ponto 04 encontra-se na Travessa Brasílio de Lara, 687, Bairro Alto - esquina com a Rua Brasílio de Lara, coordenadas $25^{\circ} 25^{\prime} 34.19^{\prime \prime} \mathrm{S}-49^{\circ} 12^{\prime} 31.97$ ” W. Este ponto fica próximo a confluência do Rio Bacacheri com o Rio Atuba. Assim como o ponto 3, embora exista mata ciliar, em ambas as margens, como as amostragens ocorreram sob uma ponte, no local exato da amostragem não existe mata ciliar, a largura do rio é de $3 \mathrm{~m}$, sua profundidade é de $40 \mathrm{~cm}$, o fundo possui lodo e cascalho, o fluxo da água é lento e pode ser constatado o depósito de lixo composto por latas, vidros, plásticos e papelão. 


\section{Parâmetros físico-químicos}

Em cada ponto foram coletados 2 litros de água para as análises dos parâmetros físico químicos e as análises descritas abaixo foram realizadas no Laboratório de Análises Toxicológicas e Ambientais (LATAM) utilizando as metodologias recomendadas pelo Standard Methods of the Examination of Water and Wastewater (APHA, 2005).

\section{Determinação do pH}

O potencial hidrogeniônico $(\mathrm{pH})$ foi medido através de um pHmetro (pHTester-pH107). Após a coleta da água a análise foi realizada sucessivamente (CRUCILO, 2007).

\section{Determinação da Temperatura}

A análise foi realizada com um termômetro inserido no recipiente contendo a água coletada e permaneceu em contato por algum tempo com a mesma até que se atingisse o equilíbrio térmico.

\section{Determinação do Oxigênio Dissolvido (OD)}

A amostra foi coletada em frasco esterilizado e a leitura do OD foi realizada através do oxímetro (Lutron-DO-5510), no próprio local da coleta (CRUCILO, 2007).

\section{Demanda Bioquímica de Oxigênio (DBO)}

A DBO foi determinada por titulometria, após incubação por 5 dias a $20^{\circ} \mathrm{C}$, associada à fração biodegradável dos componentes orgânicos carbonáceos, uma medida do oxigênio consumido após 5 dias pelos microrganismos na estabilização bioquímica da matéria orgânica, segundo a metodologia descrita pelo Standard Methods for Examination of Water and Wastwater (APHA, 2005).

\section{Determinação da Demanda Química de Oxigênio (DQO) em refluxo fechado}

A DQO foi determinada pelo método do refluxo fechado seguido de espectrofotometria, segundo metodologia descrita pelo Standard Methods for Examination of Water (APHA, 2005). 


\section{Análise de Óleos e Graxas (OG)}

Para a análise de Óleos e Graxas (OG), determinados por gravimetria, foi utilizada a metodologia de análise estabelecida pela Companhia Ambiental do Estado de São Paulo (CETESB, 2001).

\section{Determinação de Sólidos dissolvidos ou Sólidos Sedimentáveis (SS)}

Uma porção devidamente homogeneizada da amostra foi filtrada em uma bomba a vácuo com filtro de fibra de vidro, evaporada em banho-maria e secada em estufa na temperatura de $103-105^{\circ} \mathrm{C}$. A diferença do peso da cápsula depois de filtrada a amostra, com a cápsula cheia, indicará a quantidade de sólidos existentes (CRUCILO, 2007, APHA, 2005).

\section{Determinação da Turbidez}

O valor de turbidez foi realizado através do método nefelométrico, cujo resultado é obtido direto no turbidímetro e cujos valores são demonstrados em unidade NTU (CETESB, 2001).

\section{Verificação da biodegradabilidade}

Para a verificação da biodegradabilidade dos compostos presentes no corpo d'água, foi realizada a relação DQO/DBO (JARDIM; CANELA, 2004).

Os dados de precipitação e temperatura no ano de 2016 foram obtidos no website do Instituto Nacional de Pesquisas Espaciais - INPE.

\section{Resultados}

\section{Dados de precipitação e temperatura}

Durante o período de coleta, a precipitação média variou entre aproximadamente $80 \mathrm{~mm}$ (agosto - menores valores de precipitação) e aproximadamente 140 mm (outubro - maiores valores de precipitação). Quanto à temperatura média, foi verificada uma variação entre $12^{\circ} \mathrm{C}$ (junho) e $18^{\circ} \mathrm{C}$ (novembro) (figura 1 ). 
Figura 1: Dados de precipitação e temperatura na cidade de Curitiba/PR no ano de 2016.

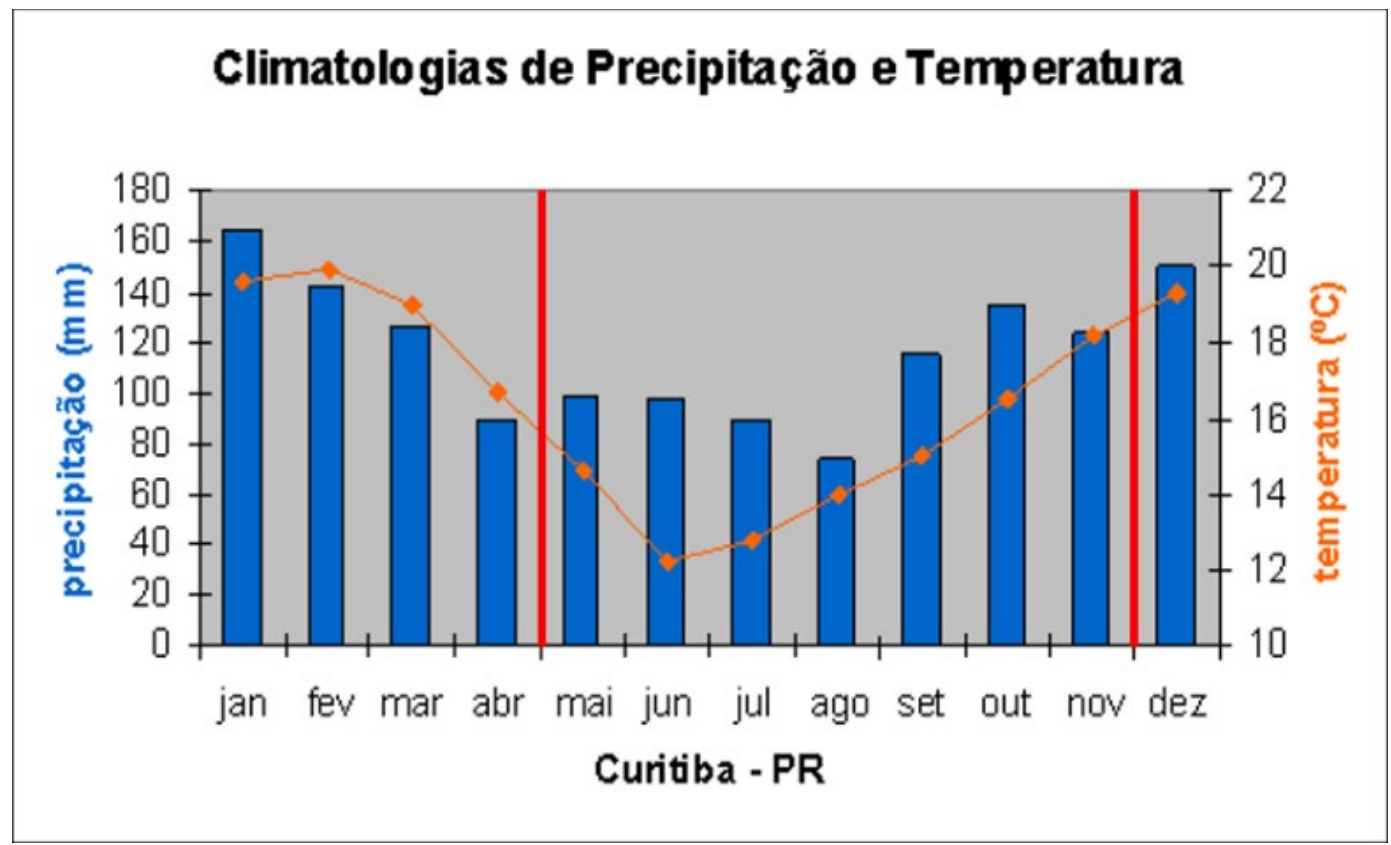

Fonte: Instituto Nacional de Pesquisas Espaciais - INPE (2018).

\section{Parâmetros físico-químicos}

Os resultados das análises dos parâmetros físico-químicos do rio Bacacheri obtidos ao longo das cinco coletas estão apresentados na figura 2. 
Figura 2: Parâmetros físico-químicos avaliados no rio Bacacheri (Curitiba/PR) durantes os meses de maio a novembro (exceto julho)

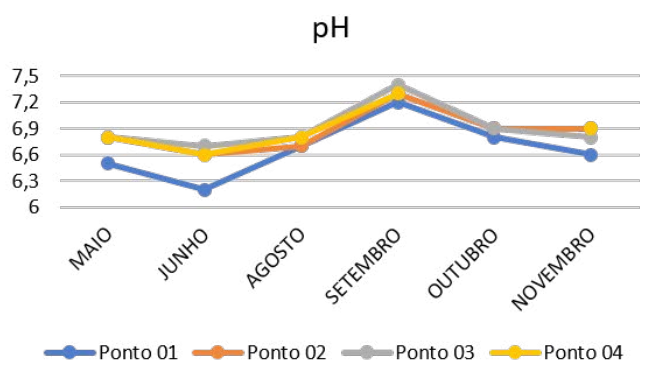

\section{OXIGÊNIO DISSOLVIDO}

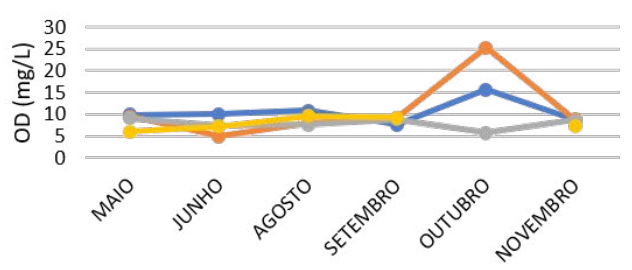

$\simeq$ Ponto $01 \leadsto$ Ponto $02 \simeq$ Ponto $03 \cong$ Ponto 04

\section{DEMANDA QUÍMICA DE OXIGÊNIO}

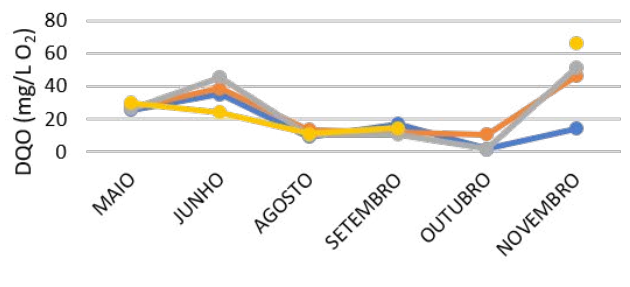

$\longrightarrow$ Ponto $01 \simeq$ Ponto $02 \longrightarrow$ Ponto $03 \cong$ Ponto 04

\section{ÓLEOS E GRAXAS}

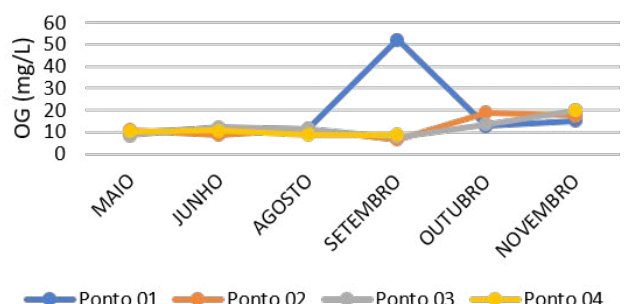

Fonte: Elaborado pelos autores.
TEMPERATURA

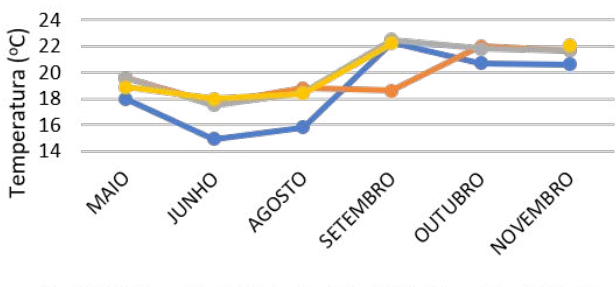

DEMANDA BIOQUÍMICA DE OXIGÊNIO

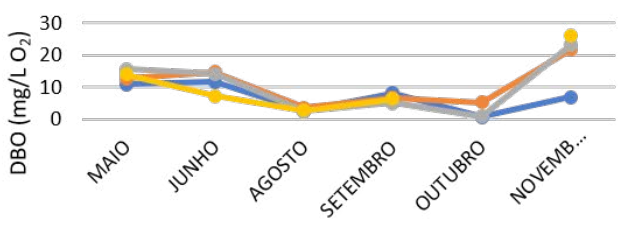

-Ponto $01-$ Ponto $02 \simeq$ Ponto $03-$ Ponto 04

\section{TURBIDEZ}

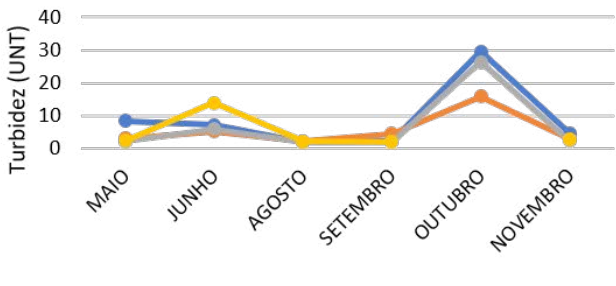

SÓLIDOS EM SUSPENSÃO

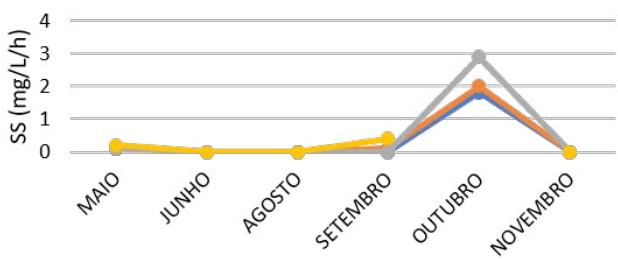

$\longrightarrow$ Ponto $01 \longrightarrow$ Ponto $02 \backsim$ Ponto $03 \longrightarrow$ Ponto 04 
Em relação ao pH, em todos os pontos de coleta, o mês de setembro apresentou, em média, os maiores valores de $\mathrm{pH}$, ao passo que no mês de junho apresentou, em média, os menores valores. O maior valor registrado para este parâmetro ocorreu no mês de setembro (7,4 - ponto 03$)$, contrariamente ao menor valor apontado que foi no mês de junho $(6,2)$ no ponto de coleta 01 . Estes valores de $\mathrm{pH}$, em todos os pontos, indicam uma variação de levemente ácido a levemente neutro-alcalino da água do rio Bacacheri durante os meses de avaliação.

Em relação a temperatura da água do rio $(\mathrm{T})$, nota-se que os maiores valores de temperatura registrados ocorreram no mês de setembro, exceto para o ponto de coleta 02 e, inversamente, os menores valores registrados para este parâmetro ocorreram no mês de junho. A maior temperatura registrada ocorreu no mês de setembro $\left(22,5^{\circ} \mathrm{C}\right)$ no ponto de coleta 03 , e a menor, foi registrada no mês de junho no ponto $01\left(14,9^{\circ} \mathrm{C}\right)$.

O oxigênio dissolvido (OD) apresentou pouca variação entre os meses de maio a setembro, no entanto, no mês de outubro, foi observado uma grande variação em todos os pontos de coleta, sendo o maior valor observado no ponto de coleta $02(25,2$ $\mathrm{mg} / \mathrm{L})$ e o menor valor foi obtido no ponto $03(5,8 \mathrm{mg} / \mathrm{L})$.

A demanda bioquímica de oxigênio (DBO), exceto para o ponto de coleta 01 , apresentou seus maiores valores médios no mês de novembro, ao passo que os menores valores ocorreram no mês de outubro, seguido do mês de agosto. $\mathrm{O}$ maior valor de DBO obtido foi no ponto de coleta $04(26,2 \mathrm{mg} / \mathrm{L})$ no último mês e o menor valor foi registrado no ponto 01 no mês de outubro $(0,7 \mathrm{mg} / \mathrm{L})$.

A demanda química de oxigênio (DQO) apresentou um perfil bastante semelhante à $\mathrm{DBO}$, com maiores e menores valores médios em novembro e outubro, respectivamente (exceto para o ponto 01). Além disso, o maior valor de DQO foi registrado no mês de novembro $(66,3 \mathrm{mg} / \mathrm{L})$ em novembro, e o menor valor foi registrado no ponto 01 e 03 no mês de outubro $(1,7 \mathrm{mg} / \mathrm{L})$.

Ainda, tanto para os valores de DBO quanto de DQO, os resultados apontam uma tendência ao decréscimo dos valores destes parâmetros de maio a outubro, com elevação no mês de novembro.

Para os parâmetros de turbidez e sólidos em suspensão (SS) nota-se que os maiores valores estão no mês de outubro. Já para os óleos e graxas (OG), nota-se uma estabilização dos valores entres os meses de maio a setembro, como um pico este nesse último mês no ponto de coleta 01 . 


\section{Biodegradabilidade}

A verificação da biodegradabilidade dos compostos presentes no rio Bacacheri durante os meses de coleta foi verificada por meio da razão DQO/DBO e está apresentada na figura 3 .

Figura 3: Avaliação da Biodegradabilidade do rio Bacacheri durante os meses de maio a novembro. Valores de referência: $<2,5$ - facilmente biodegradável; 2,5 e 5,0 - passível de biodegradação; > 5,0 biorefratário

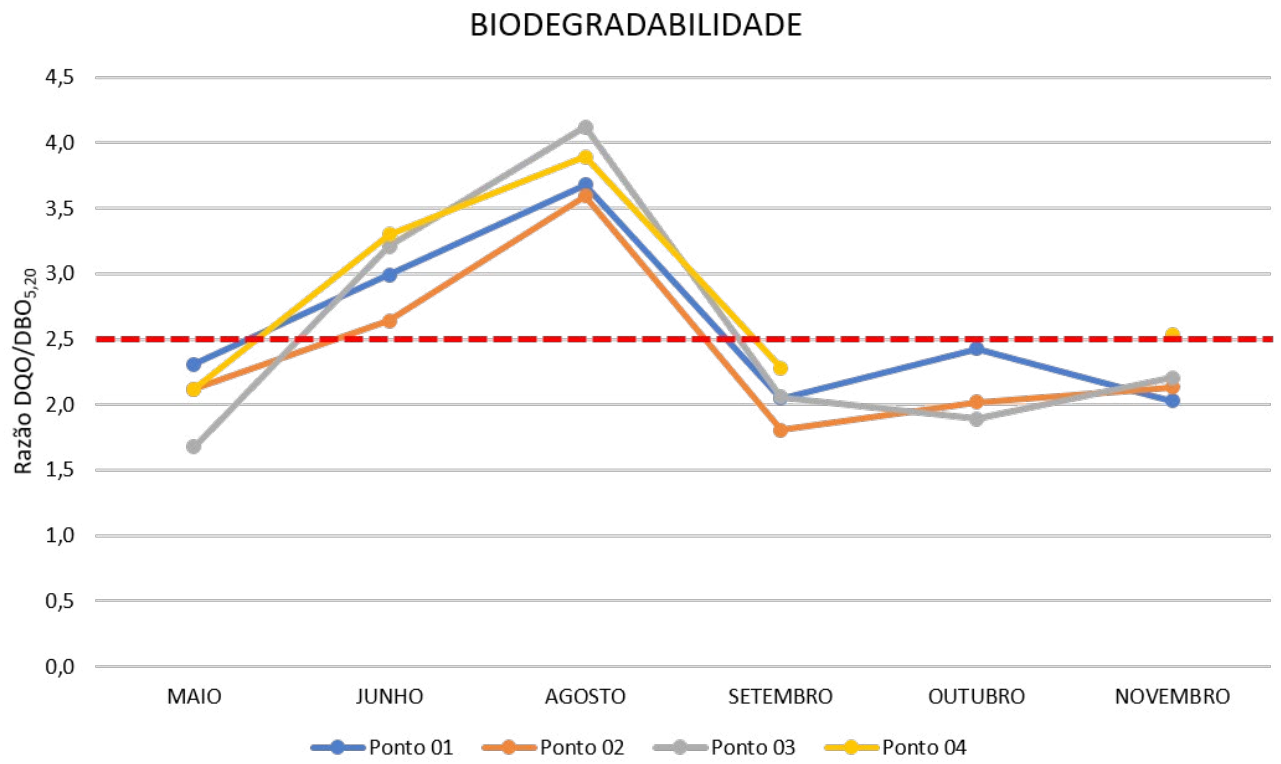

Fonte: JARDIM; CANELA, 2004).

A relação do grau de degradabilidade da água foi estabelecida através da relação DQO/DBO. Obteve-se um valor de 2,29 para o ponto 2 e 2,37 para o ponto 3 , indicando um material facilmente biodegradável. Para o ponto 1 foi obtido um valor de 2,5 e para o ponto 4 , um valor de 2,5 , indicando um poluente biodegradável.

\section{Discussão}

Analisando os valores de $\mathrm{pH}$ obtidos para os 4 pontos de coleta, observa-se que eles seguem o recomendado pela Resolução CONAMA nº 357/2005 para a Classe 2, que estabelece os valores de $\mathrm{pH}$ entre 6,0 a 9,0. Ainda, nota-se que a variação dos 
valores de $\mathrm{pH}$ é acompanhada pela variação de temperatura, com a média mais alta no mês de setembro e a mais baixa no mês de junho.

Estudos mostram que há uma relação inversamente proporcional entre a temperatura e a concentração de OD na água (CARVALHO et al., 2000). No presente estudo, nota-se esta relação inversa apenas no mês de setembro e novembro, apontando que a temperatura da água não parece ter influência direta nesse parâmetro. Embora a baixa concentração de OD não possa ser explicada pelos valores de temperatura neste estudo especificamente, aos valores apresentados mostram que estão em conformidade com as determinações mínimas para rios da Classe 2 (não inferior a $4 \mathrm{mg} / \mathrm{L} \mathrm{O}_{2}$ ) (CONAMA, 2005, p. 11).

Assim, outra hipótese é que esta diminuição da concentração de OD poderia ser explicada pela decomposição da matéria orgânica por meio de processos oxidativos (SIQUEIRA et al, 2011), o que poderia ser corroborado por valores elevados de turbidez, encontrados neste estudo, os quais podem indicar a presença de matéria orgânica no corpo hídrico. Os altos valores de turbidez verificados no mês de outubro podem indicar a presença de altas quantidades de matéria orgânica no rio Bacaheri o que deveria ser corroborado com baixos valores de OD porém, este fato também não é observado.

Por fim, a explicação mais plausível para o aumento da OD no mês de setembro pode ser explicada pelo aumento do regime de chuvas naquele mesmo mês. De acordo com estudos de Pereira et al., (2010) e Nozaki et al. (2014) os níveis de concentração do OD podem aumentar devido à turbulência na água. Destaca-se que as inúmeras moradias as margens do rio e o intenso grau de urbanização que permeia toda a sua extensão podem ter influenciado nos baixos níveis de oxigênio dissolvido nos outros meses devido a maior quantidade de esgoto doméstico e efluentes industriais lançados neste corpo de água (zona de degradação).

Como mencionado, o despejo de água residuárias sem tratamento prévio pode aumentar consideravelmente o aporte de matéria orgânica nestes locais sobretudo quando há baixa vazão e volume de água., o que favorece o aumento da DBO local (MORRISON et al., 2001).

No rio Bacacheri, os altos valores de DBO e DQO podem indicar a presença de matéria orgânica, no entanto, os valores destes parâmetros também foram baixos no mês de outubro, indicando que provavelmente outro fator está influenciando os baixos valores de oxigênio dissolvido no local. A alta DBO e DQO no mês de novembro mostra a possibilidade do aumento de despejos domésticos e/ou industriais no rio 
Bacacheri. Vale destacar que as médias obtidas para DBO variaram de 6,8 a 11,3 entre os pontos analisados ficando acima de $5 \mathrm{mg} / \mathrm{LO}_{2}$.

Pode se observar em todos os pontos, que na terceira e quinta coleta, os valores de DBO ficaram dentro do valor determinado pelo CONAMA, entre 0,7 a 3,7. Adicionalmente, os valores da DQO variaram de 17,0 mg/L a 29,1mg/L. Embora a DQO não seja um parâmetro exigido pela legislação, ele é muito importante na pesquisa de efluentes industriais e esgotos sanitários. Essa análise associada com a DBO é básica para verificar a biodegradabilidade dos despejos (CETESB, 2016).

De acordo com os resultados obtidos e apresentados na figura 3, nenhum ponto de coleta apresentou valores acima de 5,0, o que indica não ser um rio biorefratário. Além disso, durante a maioria das coletas (maio, setembro, outubro e novembro) o rio se mostrou facilmente biodegradável ( $\mathrm{DQO} / \mathrm{DBO}<2,5)$, embora, em todos os pontos de coleta, nos meses de junho e agosto, ele foi enquadrado como passível de biodegradação $(2,5>\mathrm{DQO} / \mathrm{DBO}<5,0)$. Quando o valor da relação de biodegrabilidade DQO/DBO for menor que 2,5, o rio será classificado como facilmente biodegradável, se o valor encontrado estiver entre 2,5 e 5,0 será enquadrado como passível de biodegradação e se a relação for maior que 5,0 o rio será classificado como biorefratário (JARDIM; CANELA, 2004).

A respeito da biodegrabilidade Telles (2013), cita que:

ADQO é um parâmetro indispensável nos estudos de caracterização de esgotos sanitários e de efluentes industriais. A DQO é muito útil quando utilizada conjuntamente com a DBO para observar a biodegrabilidadde de despejos. Sabe-se que o poder de oxidação do dicromato de potássio é maior do que o que resulta mediante a ação de microrganismos, exceto raríssimos casos como hidrocarbonetos aromáticos e piridina. Desta forma, os resultados da DQO de uma amostra são superiores aos de DBO. Como na DBO mede-se apenas a fração biodegradável, quanto mais este valor se aproximar da DQO significa que mais facilmente biodegradável será o efluente (TELLES, p. 227, 2012).

O método padrão para determinação da DQO utiliza dicromato de potássio como agente oxidante (BUENO, 2011). De acordo com Medeiros et al. (2006):

O método de digestão do dicromato, trata-se de uma reação de oxidação em meio fortemente ácido e elevada temperatura na presença de um catalisador (o sulfato de prata). É usado o dicromato de potássio (cromo na forma de $\mathrm{Cr}^{6+}$ ) devido a sua forte capacidade oxidante, facilidade de manipulação e aplicabilidade, além de ser um padrão primário. A utilização de um catalisador, como o sulfato de prata, é necessária para tornar possível a oxidação de compostos alifáticos de cadeia reta. Após a oxidação da matéria orgânica presente, a DQO é obtida diretamente $\left(\mathrm{mg} \mathrm{O}_{2} / \mathrm{L}\right)$ no espectrofotômetro DR2000, através de uma curva padrão inserida no laboratório (MEDEIROS et al., 2006, p. 05). 
Durante os meses de coleta, de maneira geral, observou-se que houve uma uniformidade de resultados nos pontos utilizados. Segundo Pinho et al. (2010) não há necessidade de muitos pontos de coleta quando o corpo hídrico possui alto grau de urbanização ao longo do seu curso.

O controle da qualidade da água, para diferentes finalidades deve ser embasado na legislação vigente que estabelece e padroniza os requisitos mínimos necessários para que o corpo de água tenha o uso previsto. Nesse sentido, a resolução CONAMA n. 357 de março de 2005, estabelece padrões de qualidade dos corpos receptores, lançamento de efluentes nos corpos d'água e padrões de balneabilidade. Já os padrões de potabilidade, usados principalmente no abastecimento urbano, são regidos pela portaria do Ministério da Saúde (MS) de número 2.914 de 12 de dezembro de 2011 (BRASIL, 2005; BRASIL, 2011).

O Rio Bacacheri está incluído na seção de águas doces destinadas a preservação do equilíbrio natural das comunidades aquáticas, não sendo utilizada para consumo humano. Apesar de não ter essa função, o rio é inserido na resolução do CONAMA n⿳ 357 , de 17 de março de 2005, onde diz que a presença de apenas uma colônia de agentes do grupo de coliformes fecais em água já caracteriza como contaminação do meio (SUREHMA, 1992; CONAMA, 2005, SEMA, 2010).

Segundo a Série Histórica das Bacias Hidrográficas do Paraná da Secretaria Estadual de Meio Ambiente e Recursos Hídricos (SEMA):

A condição ruim, em termos de qualidade, no corpo principal do Alto Rio Iguaçu, é principalmente influenciada pelos afluentes da margem direita, que drenam a cidade de Curitiba, como os Rios Belém, Ivo, Atuba, Bacacheri, Padilha, Barigui, Água Verde, Fanny e Parolin, que estão caracterizados como "Poluídos e Extremamente Poluídos", com altos teores de coliformes fecais e matéria orgânica e baixa concentração de oxigênio dissolvido, sendo, portanto, incapazes de manter vida aquática (SEMA, 2010, p. 35).

No trabalho enfocando a análise microbiológica do rio Bacacheri, Silveira (2018) verificou o desenvolvimento de colônias de bactérias nas amostras de todos os pontos analisados e concluiu que o rio está comprovadamente poluído e que sua água é prejudicial à saúde humana.

A turbidez de uma amostra de água é o grau de atenuação de intensidade que um feixe de luz sofre ao atravessá-la devido à presença de sólidos em suspensão, como partículas inorgânicas (areia, silte, argila) e detritos orgânicos, como algas e bactérias, plâncton em geral, etc. (NANES et al., 2012). Os parâmetros cor e turbidez são indicativos da presença de sólidos dissolvidos em suspensão ou material 
em estado coloidal, sejam eles orgânicos ou inorgânicos (CAPPI et al., 2012). No presente trabalho os valores para turbidez foram inferiores ao indicado pela portaria de potabilidade. No entanto, nota-se um pico no mês de setembro na avaliação da presença de óleos de graxas o que pode ser explicado pelo aumento na precipitação de chuvas naquele mês o que também poderia explicar o aumento dos valores dos sólidos em suspensão no mês seguinte.

\section{Conclusão}

Os resultados obtidos neste trabalho permitem concluir que, o rio Bacacheri ainda pode ser classificado um rio classe 2 segundo a resolução CONAMA no ${ }^{3}$ 357/2005, embora as outras análises necessárias não tenham sido realizadas neste trabalho. Ainda, pode-se concluir que nas áreas mais próximas a sua nascente e sua foz, é um rio facilmente biodegradável e nas suas áreas intermediárias ele é passível de degradação. Embora sua turbidez esteja abaixo do indicado pela portaria de potabilidade, o rio Bacacheri pode ser considerado como um rio poluído.

\section{Physico-chemical quality monitoring of water of Bacacheri river, Curitiba - Paraná - Brazil}

\section{Abstract}

The disorderly growth of the city of Curitiba, capital of the state of Paraná (Brazil), has led to an increase in anthropogenic actions on most of its urban rivers, such as the discharge of in natura wastewater, the dumping of domestic and industrial waste, the alteration of its body water and the deforestation of the riparian forest, which eventually determined the degradation of these water bodies. The Bacacheri River, one of the most impacted rivers in the urban area of Curitiba, has its source in the Cachoeira district, located in the northern region of the city, crossing 16 neighborhoods along its $12 \mathrm{~km}$ of length. In this context, the objective of the present study was to investigate the water quality of the Bacacheri river through physico-chemical parameters in four (04) different harvest points between June and November (except August) of 2016. The results have been shown that in the areas closer to its source and its mouth, the Bacacheri river is easily biodegradable and in its intermediate areas it is more degradable than the other harvest points. Although its turbidity is below the limit established by the Brazilian guidelines which provides for the control and surveillance procedures of water quality for human consumption and its potability standard (Health Ministry Legislation number 2.914 / 2011), the other results indicate that It deals with a polluted river, and the intervention of competent government agencies is necessary to enable the pollution of this river.

Keywords: Water quality. Bacacheri River. Physico-chemical endpoints. 
ABOWEI, JFN. Salinity, dissolved oxygen, $\mathrm{pH}$ and surface water temperature conditions in Nkoro River, Niger Delta, Nigeria. Advance Journal Food Science and Technology, v. 2, n. 1, p. 16-21, 2010.

APHA. American Public Health Association. Standard Methods for the Examination of Water and Wastewater. 21. ed. Washington: APHA; 2005.

BRASIL. Agência Nacional de Águas - ANA. Cuidando das águas: soluções para melhorar a qualidade dos recursos hídricos / Agência Nacional de Águas, Programa das Nações Unidas para o Meio Ambiente. 2. ed. Brasília: ANA, 2013.

BRASIL. Agência Nacional de Águas - ANA. Relatório de Conjuntura dos Recursos Hídricos traz balanço da situação e da gestão das águas no Brasil. 2013. Disponível em: <https://www.ana.gov. br/noticias-antigas/relata3rio-de-conjuntura-dos-recursos-hadricos.2019-03-15.8720485917>. Acesso em: 19 set. 2018.

BRASIL. Conselho Nacional do meio ambiente - CONAMA, Resolução 357 de 17 de março de 2005. Disponível em: <http://www.mma.gov.br/port/conama/res/res05/res35705.pdf>. Acesso em: 19 set. 2018.

BRASIL. Ministério da Saúde. Portaria nํㅜㄹ.914, de 12 de dezembro de 2011. Dispõe sobre os procedimentos de controle e de vigilância da qualidade da água para consumo humano e seu padrão de potabilidade. http://site.sabesp.com.br/uploads/file/asabesp_doctos/kit_arsesp_portaria2914. pdf>. Acesso em: 19 set. 2018.

CAPPI, Nanci; AYACH, Lucy Ribeiro; SANTOS, Tânia Mara Baptista dos; GUIMARÃES, Solange Terezinha de Lima. Qualidade da água e fatores de contaminação de poços rasos na área urbana de Anastácio (MS). Geografia Ensino \& Pesquisa, v. 16, n. 3, p. 77-91, 2012.

CARVALHO, Vininha F. O direito à água é um direito humano e a sustentabilidade de seu uso não deve ser só econômica, mas humana, cultural, ambiental e política. 2007. Disponível em: <http://ecoviagem.uol.com.br/fique-por-dentro/artigos/meio-ambiente/22-de-marco-dia-mundial-da-agua-6773.asp>. Acesso em: 19 set. 2019.

CETESB. Companhia Ambiental do Estado de São Paulo. Significado Ambiental e Sanitário das Variáveis de Qualidade das Águas e dos Sedimentos e Metodologias Analíticas e de Amostragem. Disponível em: <https://cetesb.sp.gov.br/aguas-interiores/wp-content/uploads/ sites/12/2017/11/Ap\%C3\%AAndice-E-Significado-Ambiental-e-Sanit\%C3\%A1rio-das-Vari\%C3\%A1veis-de-Qualidade-2016.pdf >. Acesso em: 19 set. 2019.

CRILLET, C; QUETIN, P. Effect of temperature changes on the reproductive cycle of loach in lake Geneva from 1983 to 2001. Journal of Fish Biology, v. 69, p. 518-534, 2006.

CRUCILLO, FS. Análises das Águas e Águas Residuárias. Curitiba: SENAI; 2007.

FESB/CETESB: Água: qualidade, padrões de potabilidade e poluição. São Paulo, Brasil: CETESB - Centro tecnológico de Saneamento Básico, 1969.

GODEFROID, Rodrigo Santiago; FONSECA, Luisi Santos da; SILVA, Rodrigo Cássio da. Utilização dos Peixes do Rio Bacacheri como Indicadores da Qualidade Ambiental. Revista Meio Ambiente e Sustentabilidade, Ed. Especial, v. 7, n. 3, p. 675-690, jul.-dez. 2014. 
GRASSI, Marco Tadeu. Aguas no planeta Terra. Cadernos Temáticos de Química Nova na Escola, edição especial, maio 2001.

INPE. Instituto Nacional de Pesquisas Espaciais. Monitoramento Brasil. 2018. Disponível em: <http://clima1.cptec.inpe.br/monitoramentobrasil/pt>. Acesso em: 09 out. 2018.

IPPUC. Recursos hídricos. 2010. Disponível em: <http://multimidia.curitiba.pr.gov. br/2010/00085317.pdf>. Acesso em: 19 set. 2018.

JARDIM, Wilson F.; CANELA, Maria Cristina. Fundamentos da Oxidação Química No Tratamento de Efluentes e Remediação de Solos. Campinas: UNICAMP, 2004.

LAWSON, EO. Physico-chemical parameters and heavy metal contents of water from the mangroves swamps of logos lagoon, logos, Nigeria, Advances in Biological Research, v. 5, n. 1, p. 08-21, 2011.

MEDEIROS, Maria Aparecida Carvalho de; VENDEMIATTI, Josiane Aparecida de Souza; DRAGONI SOBRINHO, Geraldo; ALBUQUERQUE, Anjaína Fernandes de. Química Sanitária e Laboratório de Saneamento II. Universidade Estadual De Campinas, Centro Superior De Educação Tecnológica, Tecnologia em Saneamento Ambiental, 2006.

MORRISON, G; FATOKI, OS; PERSSON, L; EKBERG, A. Assessment of the impact of point source pollution from the Keiskammahoek Sewage Treatment Plant on the Keiskamma River $\mathrm{pH}$, electrical conductivity, oxygen demanding substance (COD) and nutrients. Water SA, v. 27, n. 4, p. 475-480, 2001.

NANES, Patrícia Lanne Marques de Farias; NANES, Dayan Pereira; FARIAS, Sylvia Elaine Marques de. Qualidade das águas subterrâneas de poços tipo cacimba: um estudo de caso da Comunidade Nascença - município de São Sebastião - AL. In: III Congresso Brasileiro de Gestão Ambiental; nov. 19-22; Goiânia; Goiás; 2012.

NEVES, Flávia Maria Chami; CASTRO, Fábio Branco Godinho de; GODEFROID, Rodrigo Santiago; WAGNER, Ricardo; SANTOS, Vera Lucia Pereira dos. Avaliação da Qualidade da Água do Rio Bacacheri, Curitiba/Pr. Revista Meio Ambiente e Sustentabilidade, Ed. Especial, v. 7, n. 3, p. 659-674, jul.-dez, 2015.

NOZAKI, Cássia Tiemi; MARCONDES, Marta Angela; LOPES, Fernanda Amate; SANTOS, Karoline Ferreira dos; LARIZZATTI, Paula Simone da Costa. Comportamento temporal de oxigênio dissolvido e pH nos rios e córregos urbanos. Atas de Saúde Ambiental - ASA, v. 2, n.1, p. 29-44, 2014.

NOZAKI, Cássia Tiemi; MARCONDES, Marta Angela; LOPES, Fernanda Amate; SANTOS, Karoline Ferreira; LARIZZATTI, Paula Simone da Costa. Comportamento temporal de oxigênio dissolvido e pH nos rios e córregos urbanos. Atas de Saúde Ambiental - Asa, São Paulo, v. 2, n. 1, p. 29-44, jan./abr. 2014.

PINTO, André Luiz Oliveira; OLIVEIRA, Gustavo Henrique; PEREIRA, Gabrielle Alberta. Avaliação da eficiência da utilização do oxigênio dissolvido como principal indicador da qualidade das águas superficiais da bacia do Córrego Bom Jardim, Brasilândia/MS. Revista Geomae, v. 1, n. 1, p. 69-82, 2010.

RIBEIRO, Neiva Cristina. Avaliação da impermeabilização e ocorrência de inundações na bacia do rio Baracheri. 2007. 123 p. Dissertação (Mestrado em Geologia), Setor de Ciências da Terra, Universidade Federal do Paraná, Curitiba, 2007. 
RICKLEFS, Robert E. A economia da natureza. Rio de Janeiro: Guanabara Koogan, 2003.

SEMA. Secretaria Estadual de Meio Ambiente e Recursos Hídricos. Bacias Hidrográficas do Paraná. Série Histórica. <http://www.meioambiente.pr.gov.br/arquivos/File/corh/Revista_Bacias_Hidrograficas_do_Parana.pdf>. Acesso em: 19 set. 2018.

SHWETA, Tyagi; BHAVTOSH, Sharma; PRASHANT, Singh; RAJENDRA, Dobhal. Water Quality Assessment in Terms of Water Quality Index. American Journal of Water Resources, v. 1, p. 34-38, 2013.

SILVEIRA, Carlos Augusto; CASTRO, Fábio Branco Godinho de; GODEFROID, Rodrigo Santiago; SILVA, Rodrigo de Cássio; SANTOS, Vera Lucia Pereira dos. Análise microbiológica da água do Rio Bacacheri, em Curitiba (PR). Engenharia Sanitária e Ambiental, v. 23, n. 5, p. 933-938, 2018.

SIQUEIRA, Laurinda Fernanda Saldanha; COSTA NETO, Jonas de Jesus Gomes; ROJAS, Mariano Oscar Anibal Ibãnez. Bioensaio e estudo da decomposição de Ruppia marítima L, da Laguna da Jansen, São Luís - MA (Brasil). Revista Acta Tecnológica, v. 6, n. 1, p. 63-72, 2011.

SUASSUNA, João. A má distribuição da água no Brasil. 2004. Repórter Brasil. Disponível em: <http://reporterbrasil.org.br/2004/04/b-artigo-b-a-ma-distribuicao-da-agua-no-brasil/>. Acesso em 19 set. 2019.

SUREMA. Superintendência dos Recursos Hídricos e Meio Ambiente. Bacia do Rio Iguaçu. Portaria SUREHMA № 020/92 de 12 de maio de 1992. Disponível em: <http://www.recursoshidricos.pr.gov.br/arquivos/File/enquadramento-b-iguacu.pdf>. Acesso em: 19 set. 2018.

TELLES, Dirceu D’ Alkmin; COSTA, Regina Helena Pacca Guimarães. Reuso da Água: conceitos, teorias e práticas. 1. ed. São Paulo: Blucher, 2007. 311 p.

TELLES, Dirceu D’ Alkmin. Ciclo ambiental da água: da chuva a gestão. 1. ed. São Paulo: Blucher, 2013. p. 227.

TUNDISI, José Galizia; TUNDISI, Takako Matsumura. Limnologia. São Paulo: Oficina de Textos, 2008.

VICTORINO, Célia Jurema Aito. Planeta água morrendo de sede: uma visão analítica na metodologia do uso e abuso dos recursos hídricos. Porto Alegre: EDIPUCRS, 2007. 231 p. 